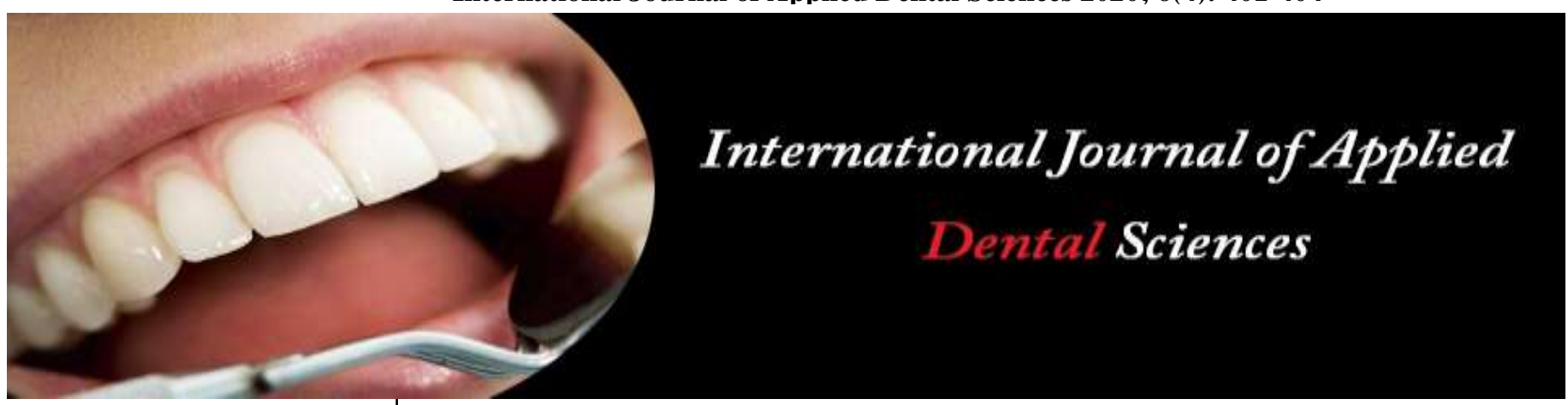

ISSN Print: 2394-7489

ISSN Online: 2394-7497

IJADS 2020; 6(4): 401-404

(C) 2020 IJADS

www.oraljournal.com

Received: 18-09-2020

Accepted: 28-10-2020

Deepak Kumar Sharma Principal, HOD, Department of

Conservative Dentistry \&

Endodontics, Jaipur Dental

College, Jaipur, Rajasthan, India

Dr. Manu Bansal

Reader, Department of

Conservative Dentistry \&

Endodontics, Jaipur Dental

College, Jaipur, Rajasthan, India

Dr. Alakesh Singha

$3^{\text {RD }}$ Year MDS Post Graduate

Student, Department of

Conservative Dentistry \&

Endodontics, Jaipur Dental

College, Jaipur, Rajasthan, India
Corresponding Author:

Dr. Alakesh Singha

$3^{\text {RD }}$ Year MDS Post Graduate

Student, Department of

Conservative Dentistry \&

Endodontics, Jaipur Dental

College, Jaipur, Rajasthan, India

\section{Maxillary lateral incisor with four root canals: A rare case report}

\section{Deepak Kumar Sharma, Dr. Manu Bansal and Dr. Alakesh Singha}

DOI: https://doi.org/10.22271/oral.2020.v6.i4f.1096

\section{Abstract}

The objective of the present study is to present a case report of endodontic treatment of a maxillary lateral incisor with 1 root and 4 root canals. The success of endodontic treatment requires knowledge of dental anatomy and its variations. The maxillary lateral incisor usually presents with one root canal system within one root. The incidence of 4 root canals in this tooth is rare. However, it must be taken into consideration, the clinical and radiographic evaluations during the endodontic treatment in order to enhance the diagnostic. The detection of all canals was achieved by examination of the pulp chamber floor with the help of the dental loupes as well as careful examination of intraoral radiographs.

Keywords: Maxillary lateral incisor, root canal anatomy, endodontic treatment, intraoral radiographs

\section{Introduction}

Complete debridement of root canal system followed by obturation in order to prevent the ingress of micro- organisms, is one of the important objectives of endodontic treatment ${ }^{[1]}$. Aberrant internal and external anatomy of teeth can pose a problem in achieving this objective. Therefore, it is important for clinicians to have thorough knowledge of anatomic variations in root canals and ways to clinically manage them to avoid any complications in the treatment ${ }^{[2]}$. Maxillary lateral incisors normally have a single root and single canal ${ }^{[3]}$. However, morphological variations for these teeth include the presence of two ${ }^{[4,5]}$, three ${ }^{[6,7]}$, four ${ }^{[8,9]}$, and even five canals ${ }^{[10]}$, usually associated with the occurrence of traumatic stimuli during tooth development process ${ }^{[11]}$. Here we represent a case of a maxillary lateral incisor with four distinct root canals.

\section{Clinical Case Report}

A 26-year-old female patient was referred to the Department of conservative Dentistry \& Endodontic, Jaipur Dental College for endodontic treatment of the maxillary left lateral incisor (tooth no 22). She reported a previous trauma in the area, about 2 years before searching for treatment. The pulp sensibility test was negative, suggesting pulp necrosis. A clinical examination revealed gingival abcess and pain when the tooth área was touched \& slight discoloration of the affected tooth [Figure 1]. A radiographic examination revealed radiolucency around the root canal, an unusual root anatomy [Figure 2]. From the clinical and radiographic findings, the maxillary lateral incisor was diagnosed as an acute periapical abscess, with an aberrant root canal system, for which root canal treatment was planned.

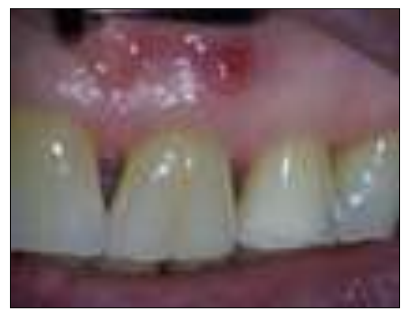

Fig 1: Clinical view shows gingivalabcess in affected area $\sim 401 \sim$ 


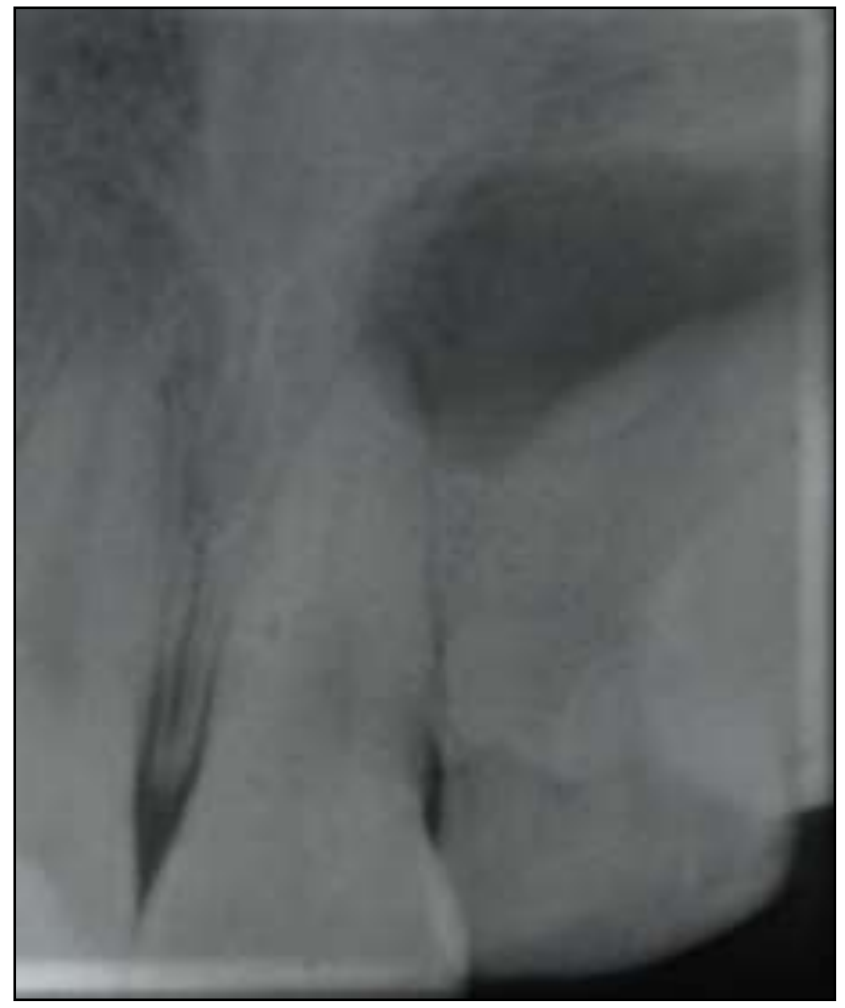

Fig 2: Pre op x ray

The patient was administered local anesthesia (2\% lignocaine with 1:100,000 epinephrine). The tooth was then accessed under rubber dam isolation after drainage of the abscess. Through pulp chamber clinical exploration with a DG-16 endodontic explorer revealed two root canal orifices in a labio-lingual direction. To locate the orifices of the mesial and distal canals, the access cavity was extended in a mesio-distal direction. Coronal flaring for all four root canal orifices was performed with Gates Glidden drills no 2,3. [Figure 3] The pulp chamber was flooded with $2.5 \% \mathrm{NaOCl}$ solution and the canals were explored with a size $10 \mathrm{~K}$ file. In all canals, the working length was determined by using an electronic apex locator (Root ZX mini, J Morita Mfg Corp., Japan). [Figure 4]

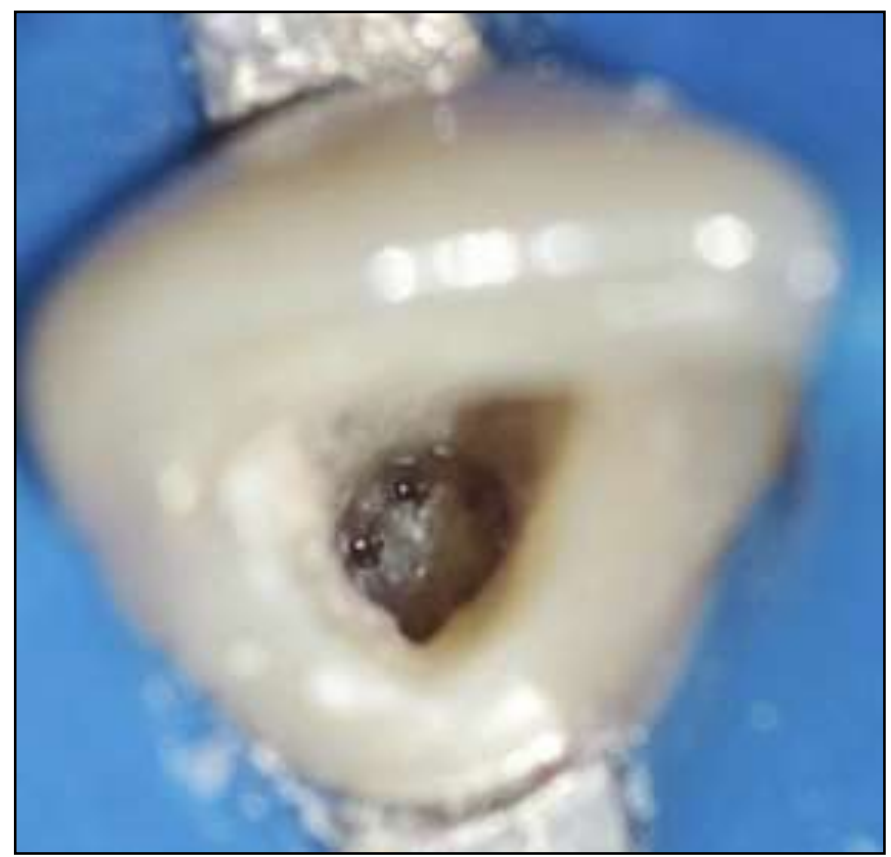

Fig 3: Distinct canal orifices seen through pulp chamber

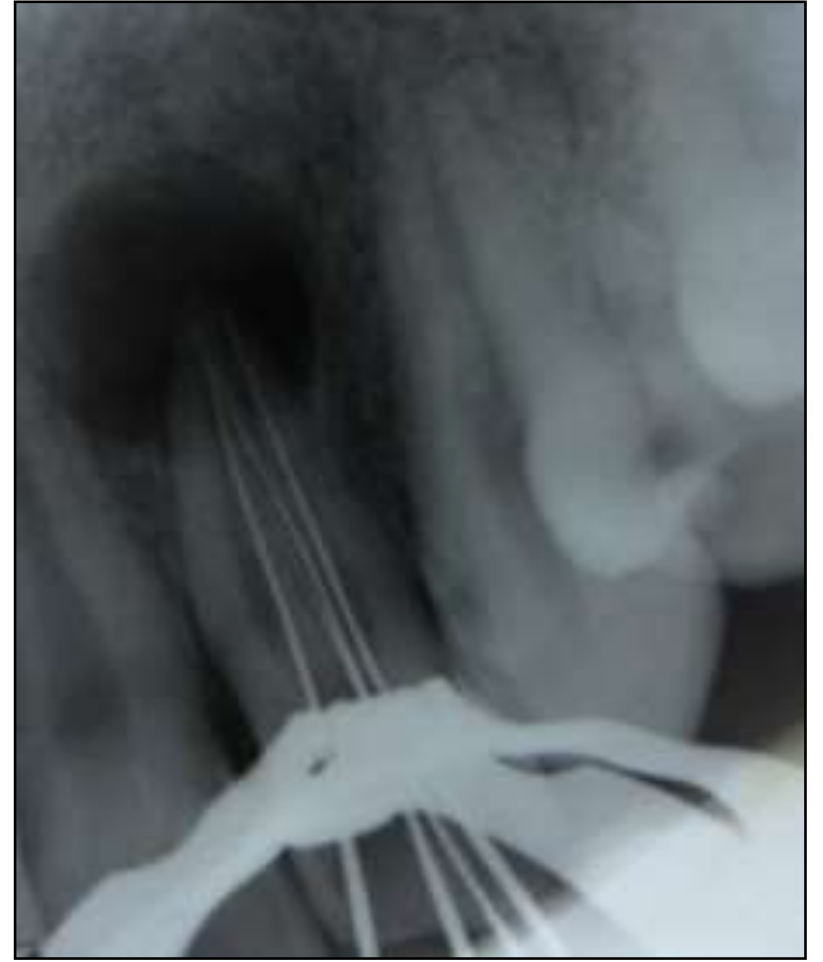

Fig 4: working length

The canals were instrumented with Protaper Universal Rotary file system using Crown-Down technique. The canals were enlarged upto a file size \# F2. At this point 2 of the mesial canals fused together. $2.5 \% \mathrm{NaOCl}$, saline solution and $2 \%$ chlorhexidine gel were used as irrigants.

Root canal treatment was carried out in two sessions. At the end of the first session, a calcium hydroxide paste was used as an intracanal medication for 2 week and temporary restoration was done (Cavit; 3M, St Paul, MN).[Figure 5]

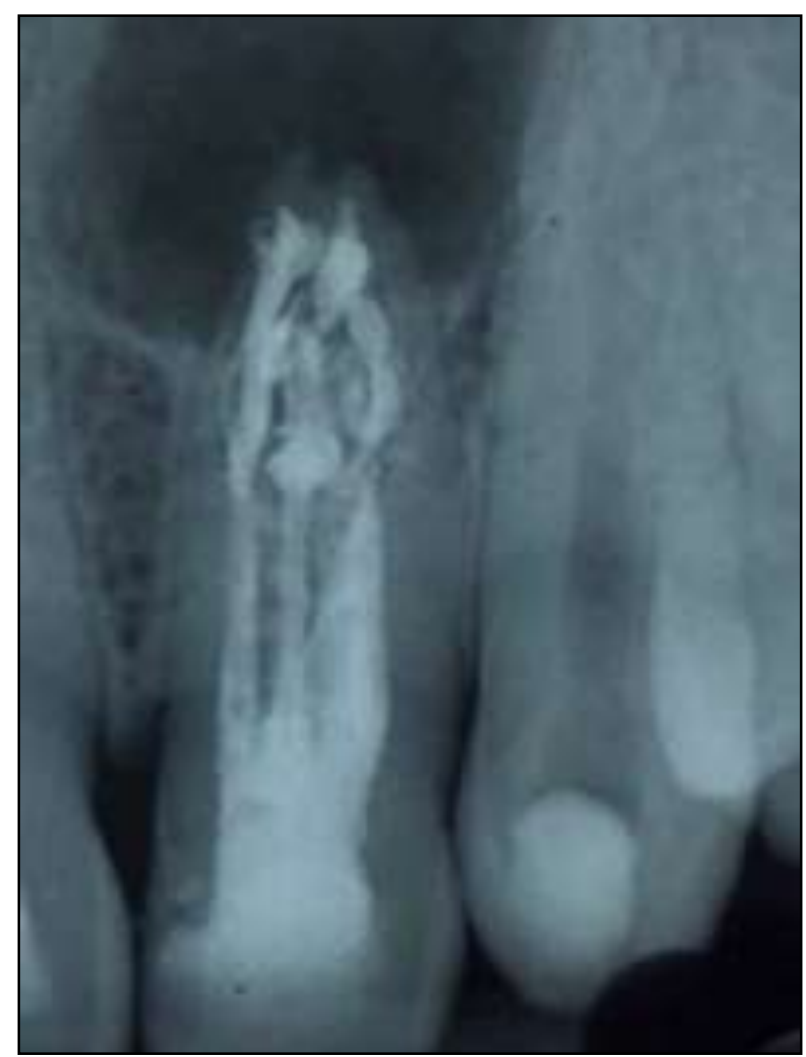

Fig 5: Calcium hydroxide intracanal medicament 
In the second session, after 15 days, the intracanal medication was removed and the canals were filled with 17\% EDTA for 3 minutes for smear layer removal, irrigated again with $2.5 \%$ $\mathrm{NaOCl}$, dried with absorbent paper points, master cone placed in all four canals \& confirmatory radiograph taken [Figure 6] and filled by lateral condensation of gutta-percha and $\mathrm{AH}$
Plus sealer (Dentsply/De Trey, Konstanz, Germany).[Figure 7]. Figure 8 shows the final X-ray after root canal therapy. The patient was observed after 7 months through clinical and radiographic examination and the tooth remained asymptomatic \& absence of periapical lesion, gingival abcess. [Figure 9, 10].

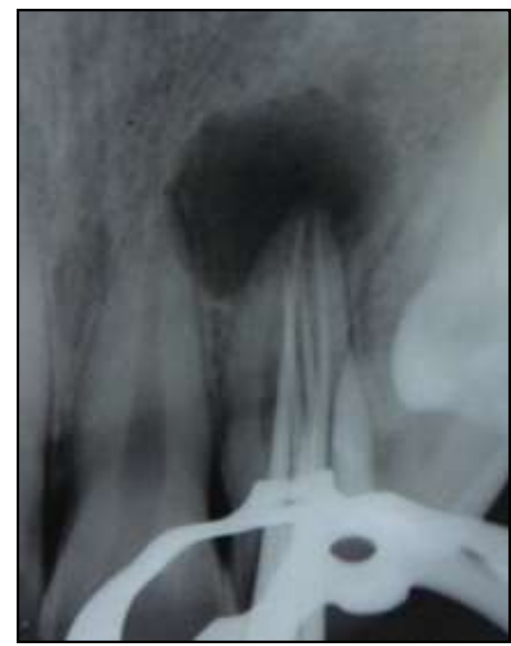

Fig 6: Mater cone xray

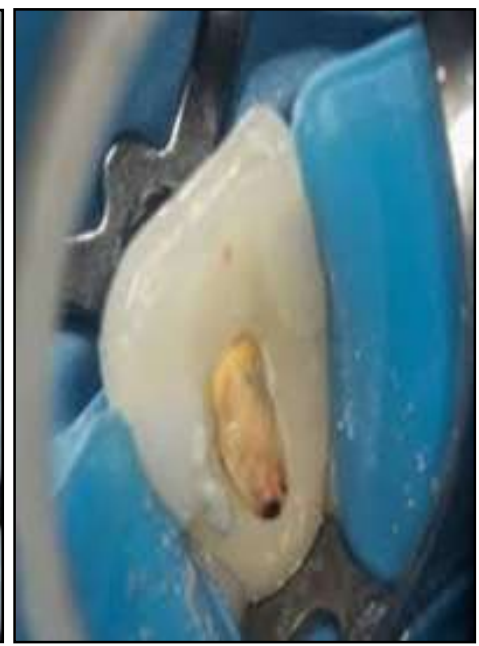

Fig 7: Obturated canal

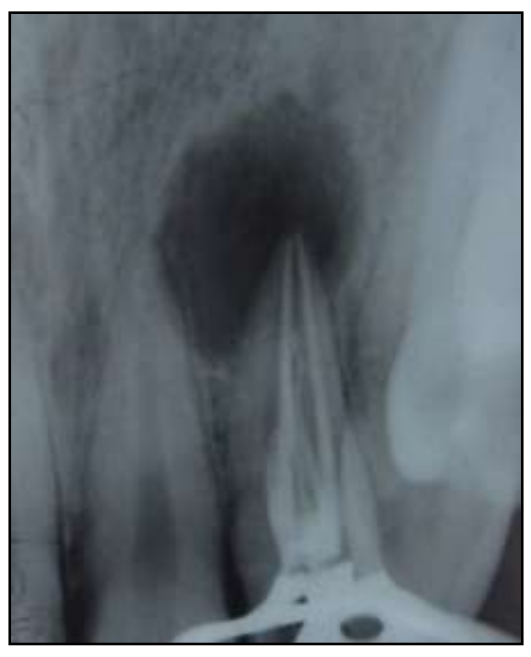

Fig 8: Post op Xray

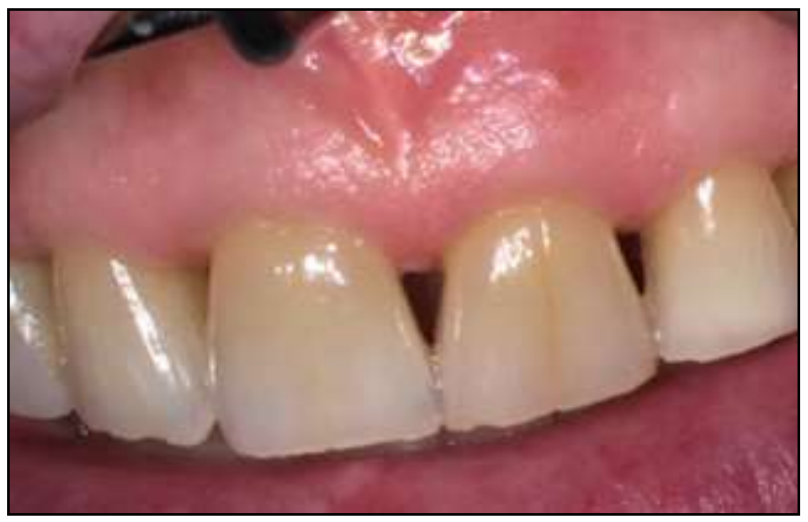

Fig 9: Clinical view shows no signs of abcess after 7 months followup

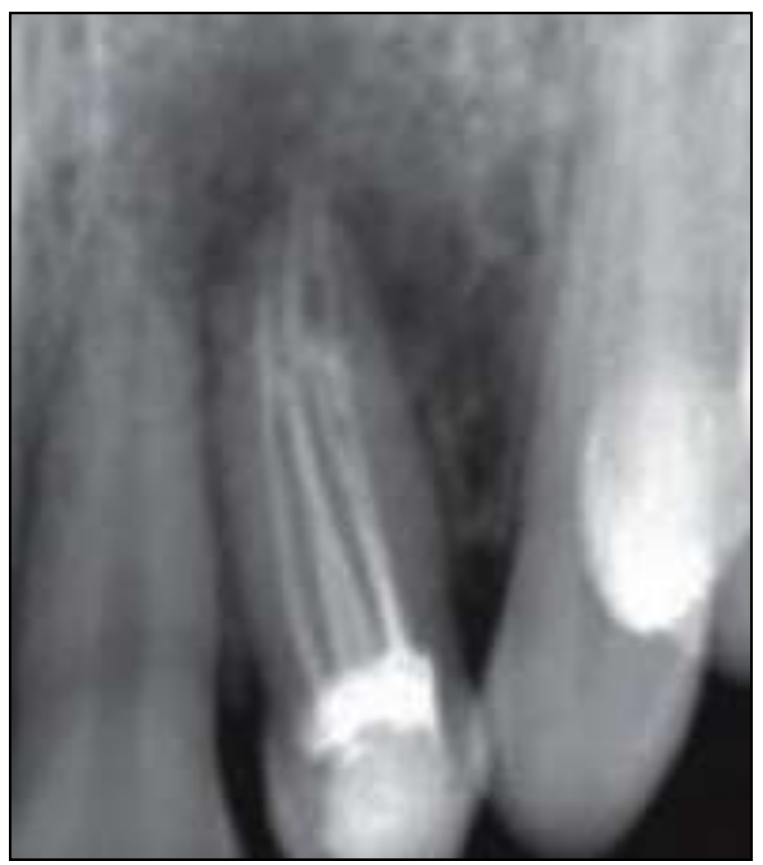

Fig 10: Absence of periapical lesion 7 months follow up xray

\section{Discussion}

Maxillary lateral incisor teeth are generally considered to be single-rooted teeth with a single canal (Burns \& Herbranson 2002) ${ }^{[12]}$. According to the literature, there are no limits for the morphological variability. Their documentation in case reports may facilitate the recognition and successful management of similar cases that should require endodontic therapy. According to Leonardo, an inability to detect, locate, negotiate, and instrument all root canals may lead to endodontic failure ${ }^{[13]}$. According to a survey, it was reported that $3 \%$ of maxillary lateral incisors may have two canals ${ }^{[14]}$. Radiographic examination is an important part in diag- nosis and treatment planning ${ }^{[15]}$.

Periapical radiographs with variations of angulation can be obtained to increase their accuracy in identifying anatomical anomalies ${ }^{[16]}$. However, conventional radiography offers limited information because it provides a two-dimensional image and there is a possibility of distortion and superimposition of structures. In the present clinical report, it was possible to visualize the canals through the evaluation of the initial X-ray. The access cavity was extended mesiodistally to improve the visibility and the access for the endodontic instrumentation that was carried out with rotating instruments. However, subsequent to the placement of the file in the mesial canal, the file in the labial canal did not reach the full working length. Hence, it was concluded that the mesial and labial root canals joined at the apical third of the root and exited through one apical foramen, whereas the distal and lingual canals had a separate path from the orifice to the exiting foramina. This pattern, of four canals within one root has not been described in any of the extensive classifications for root canal systems, proposed by various authors (Gulabivala et al. 2001, Sert \& Bayirli 2004) ${ }^{[17,18]}$.

\section{Conclusion}

Although it is considered a rare developmental dental anomaly with low prevalence, deserves attention in clinical practice. The present report is to describe a maxillary central incisor with 4 canals in a tooth with no developmental 
abnormalities. It stresses the importance of using the dental loupes during endodontic treatment as well as the necessity of being attentive for morphologic variations. Thus, this study demonstrated the importance of a correct diagnosis for the endodontic practice.

\section{Acknowledgements}

The author thanks to Dr Deepak Sharma \& Dr Manu Bansal for their clinical guidance and encouragement.

\section{References}

1. Vertucci FJ. Root canal morphology and its relationship to endodontic procedures. Endod Topics 2005;10:3-29.

2. Nair PN. On the causes of persistent apical periodontitis: A review. Int Endod J 2006;39:249-81.

3. Vertucci FJ. Root canal anatomy of the human permanent teeth, Oral Surgery, Oral Medicine, Oral Pathology 1984;58(5):589-599.

4. Lee MH, Ha JH, Jin MU, Kim YK, Kim SK. Endodontic treatment of maxillary lateral incisors with anatomical variations, Restorative Dentistry \& Endodontics 2013;38(4):253-257.

5. Mohan A, Rajesh Ebenezar A, George L, Sujathan, Josy S. Maxillary lateral incisors with two canals and two separate curved roots, Contemporary Clinical Dentistry 2012;3(4):519-521.

6. Jung M. Endodontic treatment of dens invaginatus type III with three root canals and open apical foramen, International Endodontic Journal 2004;37(3):205-213.

7. Peix-Sánchez M, MiñanaLaliga R. A case of unusual anatomy: a maxillary lateral incisor with three canals," International Endodontic Journal 1999;32(3):236-240.

8. Nosrat A, Schneider SC. Endodontic management of a maxillary lateral incisor with 4 root canals and a dens invaginatus tract, Journal of Endodontics 2015;41(7):1167-1171.

9. Kottoor J, Murugesan R, Albuquerque DV. A maxillary lateral incisor with four root canals. International Endodontic Journal 2012;45:393-397.

10. Jaikailash S, Kavitha M, Ranjani MS, Saravanan B. Five root canals in peg lateral incisor with dens invaginatus : a case report with new nomenclature for the five canals, Journal of Conservative Dentistry 2014;17(4):379-381.

11. Diab M, El-Badrawy HE. Intrusion injuries of primary incisors. Part III: effects on the permanent successors," Quintessence International 2000;31(6):377-384.

12. Burns RC, Herbranson EJ. Tooth morphology and access cavity preparation. In: Cohen S, Burns RC, eds. Pathways of the pulp. St Louis, MO, USA: Mosby Elsevier 2002, pp. 173-229.

13. Libfeld H, Stabholz A, Friedman S. Endodontic therapy of bilateral geminated permanent maxillary central incisor. J Endod 1986;12:214-6.

14. De Deus QD. Endodontia, 5th ed. Medsi: Rio de Janeiro 1992.

15. Sharma S, Grover S, Sharma V, Srivastava D, Mittal M. Endodontic and esthetic management of a dilacerated max- illary central incisor having two root canals using cone beam computed tomography as a diagnostic aid, Case Reports in Dentistry, 2014, 7. Article ID 861942

16. Garlapati R, Venigalla BS, Chintamani R, Thumu J. Retreatment of a two-rooted maxillary central incisor: A case report, Journal of Clinical and Diagnostic Research 2014;8(2):253-255.
17. Gulabivala K, Aung TH, Alavi A, Ng YL. Root and canal morphology of Burmese mandibular molars. International Endodontic Journal 2001;34:359-70.

18. Sert S, Bayirli GS. Evaluation of root canal configurations of the mandibular and maxillary permanent teeth by gender in the Turkish population. Journal of Endodontics 2004;30:391-8. 